\title{
Crític a feminista a la penalización del aborto en casos de violación sexual: una mirada interseccional a propósito del embarazo infantil(*)
}

\author{
Feminist criticism to the penalty of abortion in cases of sexual violation: an \\ intersectional look for the purpose of child pregnancy
}

\author{
Victoria Natividad Solís Peña ${ }^{(*)}$ \\ Perú - Universidad Nacional Mayor de San Marcos
}

\begin{abstract}
Resumen: El presente artículo aborda desde una perspectiva crítica feminista la problemática de la penalización del aborto en casos de violación sexual. Enfatiza y llama la atención sobre el impacto diferenciado que este uso discriminatorio del derecho penal genera en niñas menores de 14 años, a propósito de la problemática cada vez más alarmante de embarazo infantil en Perú y en América Latina. Para ello, la autora hace uso de metodologías de análisis del fenómeno legal propuestas desde los feminismos, a la luz de los estándares internacionales para la protección de la infancia y la igualdad de género, presentes en el Derecho Internacional de los Derechos Humanos.
\end{abstract}

Palabras claves: Derecho Penal - Aborto - Embarazo Infantil - Discriminación - Niñas - Derechos Humanos

\begin{abstract}
This article analyzes the problem of the criminalization of abortion in cases of sexual rape from a critical feminist perspective. It emphasizes the differentiated impact that this discriminatory use of criminal law generates in girls under 14 years of age, regarding the increasingly alarming problem of child pregnancy in Peru and Latin America. Because of this, the author uses methodologies for analyzing the legal phenomenon proposed by feminisms, in the light of the principle of Higher Interest of the Child and international standards for the protection of children and gender equality, present in the International Human Rights Law.
\end{abstract}

Keywords: Criminal Law - Abortion - Child Pregnancy - Discrimination - Girls - Human Rights

(*) Nota del Editor: este artículo fue recibido el 20 de octubre de 2019 y su publicación fue aprobada el 4 de noviembre de 2019.

$\left(^{* *}\right)$ Bachiller en Derecho por la Universidad Nacional Mayor de San Marcos (Lima, Perú). Actualmente se desempeña como asesora legal de Dirección en el Centro de la Mujer Peruana Flora Tristán y en el Programa de Derechos Sexuales y Ciudadanía en Salud de la misma institución, donde es responsable de proyectos de promoción y defensa de derechos sexuales y reproductivos. Diplomada en Maternidad Infantil en América Latina por la Universidad de la República de Uruguay. Participó como delegada nacional en el $\mathrm{V}$ Foro de Jóvenes de la VIII Cumbre de las Américas del año 2018. Ha presentado ponencias en congresos de derechos humanos nacionales y extranjeros, como el Primer Congreso Internacional sobre Argumentación, Democracia y Derechos "Argumenta Perú'2017 y el Primer Foro Mundial de Pensamiento Crítico de la 8 Conferencia Latinoamericana y Caribeña de Ciencias Sociales. Ha formado parte del Círculo de Estudios Feministas y de la Clínica Jurídica y de Litigio Estratégico de la Universidad Nacional Mayor de San Marcos. Contacto: vinasope@gmail.com 


\section{Introduc ción}

La penalización del aborto en casos de violación sexual es una de las grandes vulneraciones a los derechos humanos en América Latina y El Caribe. Comités monitores de tratados del Sistema de Derechos Humanos de Naciones Unidas (ONU) han recomendado la despenalización de la interrupción voluntaria del embarazo en estas condiciones, por las graves afectaciones que la prohibición penal genera en los derechos y la salud de las mujeres.

Mientras en las últimas décadas, países en la región, como Colombia, Chile y Bolivia, han avanzado normativamente dando cumplimiento a este estándar internacional, el Estado peruano ha hecho caso omiso, sosteniendo la penalización del aborto por esta causal, cuya no punición debería considerarse actualmente un piso mínimo en el reconocimiento del derecho a la autonomía reproductiva de las mujeres.

Como están denunciando diversas organizaciones feministas de la sociedad civil, la penalización del aborto en casos de violación genera un impacto diferenciado en los derechos humanos de las niñas menores de 14 años, quienes, al ser las principales víctimas de las denuncias por violencia sexual, se encuentran continuamente expuestas a los embarazos forzados y la obstaculización en el acceso a los servicios de salud reproductiva.

El presente artículo se propone exponer esta vulneración diferenciada en los derechos de las niñas, de la mano de los estándares internacionales sobre derechos humanos de las mujeres y la niñez, y las teorías críticas feministas que proponen una visión transformadora en el Derecho.

\section{Crítica feminista al Derecho y la penalización del aborto}

El aborto es una realidad cotidiana en la vida de las mujeres ${ }^{(1)}$ $\mathrm{y}$, sin embargo, ha sido invisibilizado de la agenda de lo público, colocándose más bien en la periferia de lo ilegítimo, en la clandestinidad y el silencio social. Las regulaciones restrictivas y sancionatorias de esta práctica, en diversas legislaciones de América Latina y el mundo, son expresión de una estigmatización afianzada desde el plano de lo jurídico.

Para comprender mejor esta afirmación, es necesario apoyarnos en teorías críticas feministas, que ponen en evidencia una problemática transversal en el Derecho, en tanto construcción social. Alda Facio, jurista costarricense, señala que las normas, principios y prácticas jurídicas han sido históricamente construidas desde una perspectiva androcéntrica, centrada en la prevalencia de lo masculino, que soslayó por mucho tiempo los derechos de otros sujetos como las mujeres, la comunidad LGTBIQ, los pueblos indígenas, las personas con discapacidad y los niños, niñas y adolescentes (Facio, 2009, pág. 191).

Consecuentemente, el Derecho no es neutro ni objetivo como se ha afirmado tradicionalmente desde las teorías positivistas, ya que suele reproducir desigualdades sociales. En ese sentido, "es susceptible de un análisis de género ${ }^{(2)}$, pues su proceso de configuración difícilmente ha escapado de las características discriminatorias con las que se ha configurado el orden social" (Ramírez, 2013, pág. 269).

La perspectiva androcéntrica afianzó durante siglos una división jerarquizante entre los sexos, a través de la legitimación de roles y estereotipos. Así, en el plano de los derechos civiles es ilustrativo recordar que tanto la legislación peruana como otras en Latinoamérica, recién a mediados del siglo pasado, empezaron a reconocer el derecho al sufragio para las mujeres y la plena ciudadanía formal que este derecho representa; su negación perduró durante buena parte de la vida republicana y detrás de esta prevalecía un estereotipo que infantilizaba a las mujeres y sus capacidades para participar en la vida pública en pie de igualdad con los hombres (Poulsen, 2018, pág. 108).

En el Derecho de Familia, el androcentrismo se reflejó en la naturalización de la posición de subordinación de las mujeres, en el matrimonio y las relaciones familiares (Fernández, 2013, pág. 251). Que actualmente contemos con normas integrales para enfrentar la violencia de género dentro y

(1) Según un estudio realizado en el año 2006 por Delicia Ferrando para el Centro de la Mujer Peruana Flora Tristán, anualmente se producen en el Perú más de 360000 abortos clandestinos.

(2) Mediante el Acuerdo Plenario $N^{\circ} 1-2011 / C J-2016$, la perspectiva de género ha sido reconocida por la Corte Suprema de Justicia de la República como una herramienta útil para los operadores de justicia en la valoración de los casos de violencia contra las mujeres. En el fundamento 10, define que permite "reconocer las relaciones de poder que se dan entre los géneros, en general en los varones (adultos) como grupo social y discriminatorias para las mujeres (es de incluir niños y niñas)". 
fuera del núcleo familiar, como la Ley 30364 -Ley para prevenir, sancionar y erradicar la violencia contra las mujeres y los integrantes del grupo familiar, es gracias a un proceso muy reciente de constitucionalización de esta rama del derecho, que ha redefinido el centro de la protección estatal en los derechos fundamentales de las personas y la prevalencia de principios constitucionales como la igualdad y no discriminación en todas las relaciones familiares y sociales (Ramírez, 2018b, pág. 317).

Además, esto se debe gracias a la incorporación en la normativa nacional de estándares internacionales, construidos a partir de la interpretación de tratados internacionales sobre derechos humanos, ratificados por nuestro país, que detentan rango constitucional en nuestro ordenamiento jurídico(3). Entre estos, la Convención para la Eliminación de todas las formas de Discriminación hacia la Mujer (CEDAW) (1979) y la Convención Interamericana para prevenir, sancionar y erradicar la Violencia contra las mujeres (Convención de Belém do Pará) (1994), las cuales se aprobaron en el marco de Naciones Unidas y el Sistema Interamericano de Derechos Humanos, respectivamente, durante un proceso ocurrido en las últimas décadas conocido como la "sensibilización progresiva del derecho internacional de los derechos humanos hacia la perspectiva de género". Este proceso se reflejó en la adopción de instrumentos y mecanismos específicos para proteger los derechos de las mujeres (García, 2013, pág. 47).

El tratamiento del aborto desde el Derecho Penal también responde a una perspectiva androcéntrica, que ha determinado a lo largo del tiempo conductas prohibidas por la ley, sin considerar las necesidades y libertades de las mujeres. Detrás de esta prohibición, subyacen estereotipos de género, como apunta Rebecca Cook y Simone Cusack (2009, pág. 29). Entre estos se encuentran los estereotipos de roles sexuales, que imponen a las mujeres la maternidad como un destino que deben asumir sin importar el origen de la gestación o si ésta no fue planificada por ausencia de información o acceso a servicios de planificación familiar, realidad que suele ser común en países como el Perú, donde no se garantiza plenamente el acceso a los métodos anticonceptivos ni la implementación de la educación sexual integral(4).

En el Derecho Comparado, identificamos tres modelos de regulación sobre aborto: (i) la penalización total, en la que es un delito en cualquier caso, como ocurre en El Salvador y República Dominicana; (ii) el modelo de permisión por plazos, en el que no se penaliza el aborto en las primeras semanas del embarazo, como sucede en Ciudad de México, Uruguay o Canadá; y (iii) el modelo de permisión por causales, en el que existen ciertos supuestos no punibles en la ley, como ocurre en la mayoría de países de América Latina (Díaz \& Ramírez, 2013, pág. 10).

Nuestra legislación abraza el último modelo, aunque sancionando el aborto de manera casi absoluta. Así se plasma en el Capítulo II del Título I de la Parte Especial del Código Penal de 1991, referido a los delitos contra la vida, el cuerpo y la salud. El tipo base del delito se encuentra en el artículo 114, que señala: "la mujer que causa su aborto, o consciente que otro le practique, será reprimida con pena privativa de la libertad no mayor de dos años o con prestación de servicio comunitario de cincuenta y dos a ciento cuatro jornadas". En el artículo 115, se prescribe una sanción para la persona que cause el aborto con el consentimiento de la gestante, estableciéndose una "pena privativa de libertad no menor de uno ni mayor de cuatro años", agravándose la misma de dos a cinco años si sobreviene la muerte de la mujer y se pudo prever este resultado. Si quien realiza el aborto con el consentimiento de la mujer, es un profesional sanitario, además de las penas mencionadas, el artículo 117 establece una sanción de inhabilitación para el ejercicio profesional.

El único supuesto de aborto no punible, que nos enmarca en el modelo de permisión por causales, es el denominado aborto terapéutico, regulado en el artículo 119, que a su tenor señala: "no es punible el aborto practicado por un médico con el consentimiento de la mujer embarazada o de su representante legal, si lo tuviere, cuando es el único medio para salvar la vida de la gestante o para evitar en su salud un mal grave y permanente". Esta excepción se debe a que, partiendo de un juicio de proporcionalidad ${ }^{(5)}$, indispensable en un Estado Constitucional, el

(3) STC N. ${ }^{\circ} 047-2004-A \mathrm{I} / \mathrm{TC} ; \mathrm{N}^{\circ} 0025-2005-\mathrm{PI} / \mathrm{TC}$ y Nº 0026-2005-PI/TC

(4) La Defensoría del Pueblo ha concluido que los materiales educativos elaborados por el Ministerio de Educación no incluyen de manera plena el enfoque de igualdad de género y la educación sexual integral, mediante el Informe de Adjuntía Nº08-2019-DP/ AAE-Enfoque de Igualdad de Género en los materiales educativos del Ministerio de Educación. Análisis de una selección para primaria y secundaria.

(5) El test de proporcionalidad parte del presupuesto que no existe ningún derecho fundamental absoluto y, en ese sentido, frente a un conflicto de derechos fundamentales, es legítimo limitar algún derecho, aplicando este test que tiene tres pasos: Análisis de 
legislador resolvió proteger los derechos de las mujeres sobre la protección de la vida del concebido, ante el evidente conflicto de derechos fundamentales presentado.

Efectivamente, desde un punto de vista constitucional, se considera que el aborto es un típico caso de conflicto de derechos, pues encontramos dos intereses iusfundamentales contrapuestos: De un lado, la protección constitucional de la vida del concebido, al que las normas reconocen como sujeto de derecho(6); y por otro, los derechos de las mujeres, como la autonomía, salud, libre desarrollo de la personalidad, integridad y vida. (Díaz \& Ramírez, 2013, pág. 69) Para resolver este conflicto en los casos en que la vida o salud de la gestante se encuentren en riesgo, el legislador peruano optó por hacer prevalecer la protección de los derechos de la mujer, dada la desproporcionada afectación que genera en sus derechos llevar adelante una gestación en dichas condiciones.

Sin embargo, en circunstancias tan lesivas de derechos fundamentales, como una violación sexual, el legislador no ha contemplado el mismo juicio de proporcionalidad para permitir la interrupción voluntaria de un embarazo producto de esta agresión. Ha fijado, solamente, una sanción atenuada, consistente en una pena privativa de libertad no mayor de tres meses (artículo 120), siempre que la gestación "sea consecuencia de una violación sexual fuera de matrimonio" y en tanto "los hechos hubieren sido denunciados o investigados, cuando menos policialmente". Como se observa, en estos casos la protección penal hacia el concebido es absoluta, en detrimento de la dignidad, el libre desarrollo de la personalidad, salud integral y otros derechos fundamentales de las gestantes víctimas de violencia sexual.

Como ha sostenido copiosa literatura científica sobre el tema, el impacto que la violencia sexual deja en la salud mental y física suele ser muy severa y tener impacto a lo largo del tiempo, situación que es agravada cuando se impone sobre la mujer víctima, una gestación a consecuencia de la agresión, la cual se convierte en un recordatorio permanente de la experiencia traumática vivida: "Se prolonga entonces el sufrimiento de la mujer y se incrementa el riesgo de que sufra una patología severa" (Rondón, 2015, pág. 31).

La perspectiva androcéntrica que sostiene esta figura penal, se aprecia también en la exigencia de una denuncia previa de la agresión sexual para que aplique la atenuante; este requisito desconoce aquello que se ha denominado "el tiempo propio de las víctimas"(7), que pone en evidencia que no todas las mujeres denuncian inmediatamente los atentados contra su libertad o indemnidad sexual. Muchas lo hacen luego de procesar el trauma psicológico que representó la agresión o el miedo al estigma social y la culpabilización, proceso que puede tomarles años, sobre todo si sufrieron la violencia siendo menores de $\operatorname{edad}^{(8)}$

Por otro lado, el artículo 120 quiebra el principio constitucional de igualdad ante la ley, porque establece una pena atenuada solamente a las mujeres solteras que aborten una gestación producto de una violación, excluyendo injustificadamente del mismo trato y grado atenuado de culpabilidad, a las mujeres casadas que interrumpen un embarazo a consecuencia de la misma agresión (Dador, 2011, pág. 4); a ellas se les sancionaría con la pena establecida en el tipo penal base del artículo 114. Nuevamente subyace un estereotipo de género: renunciar a la maternidad es más grave cuando se hace dentro del matrimonio, institución que tradicionalmente ha sido asociada a fines prevalentemente reproductivos y donde hasta la promulgación del Código Penal de 1991 se exculpaba e invisibilizaba la violación entre cónyuges.

Como puede advertirse, la ley penal reproduce una regulación injusta para los derechos reproductivos, estableciendo una defensa absoluta e irrazonable del derecho a la vida del feto, vulnerando la vida y los derechos de las mujeres que se niegan a maternar producto de una agresión sexual. Esta prohibición ha sido definida como una violación a los derechos humanos por los Comités monitores de tratados del Sistema de Derechos Humanos de las Naciones Unidas,

idoneidad, análisis de necesidad y análisis de proporcionalidad en sentido estricto. Este test ha sido utilizado en pronunciamientos del Tribunal Constitucional, tales como la STC N $579-2008-P A / T C$.

(6) Se desprende así, de acuerdo al inciso 1 del artículo 2 de la Constitución, que señala que el concebido es sujeto de derecho en todo cuanto le favorece; así mismo, según el artículo 1 del Código Civil, que establece: "La vida humana comienza con la concepción. El concebido es sujeto de derecho para todo cuanto le favorece (...)".

(7) Categoría acuñada y desarrollada por la profesora Julissa Mantilla Falcón.

(8) Al respecto, no parece importante, que tras la modificación del artículo 88-A del Código Penal, establecida mediante Ley 30838 ahora los delitos sexuales son imprescriptibles. 
que, en múltiples observaciones dirigidas al Estado Peruano, han recomendado despenalizar el aborto por esta causa.

Así, el Comité contra la Tortura, que monitorea el cumplimiento de la Convención de las Naciones Unidas Contra la Tortura y Otros Tratos o Penas Crueles, Inhumanos - Degradantes (Convención contra la Tortura), en una recomendación realizada en el año 2016, señaló que "la legislación actual restringe severamente el acceso a interrupciones voluntarias del embarazo, incluso en casos de violación, lo cual ha resultado en graves daños, incluso muertes innecesarias de mujeres, las alegaciones recibidas indican la omisión del Estado Parte en la prevención de actos que perjudican gravemente la salud física y mental de las mujeres y que constituyen actos crueles e inhumanos". ${ }^{(9)}$

Como destaca el Comité, la represión penal, en lugar de disuadir los abortos prohibidos, agudiza el problema: da origen a incontables abortos practicados de manera clandestina, que ponen en riesgo la vida, salud e integridad de las mujeres, eludiéndose de esta forma las obligaciones constitucionales del Estado en materia de salud pública. De otro lado, aunque la pena privativa de libertad establecida en el artículo 120 es simbólica y no resulte efectiva ${ }^{(10)}$, activa la persecución penal contra las víctimas de violencia sexual, generando una victimización secundaria, en tanto el Estado, que falló en prevenir la violación y garantizar una interrupción segura del embarazo, está facultado para investigarles y procesarles en tanto decidan abortar.

Por si fuera poco, la penalización del aborto supone más que la persecución de un delito; origina, de forma cada vez más visible, "la hostilidad del sistema sanitario, que infiere castigos, estigma y hace más difícil la ruta del acceso al aborto seguro. Desvirtúa así (...) la protección de la salud, vida e integridad de las mujeres" (Guerrero, Ramírez \& Gonzáles, 2019, pág. 12).

Como desarrollaremos en los siguientes acápites, las consecuencias de la penalización del aborto en casos de violación, si bien perjudican a todas las mujeres embarazadas por esta agresión, tiene un impacto diferenciado en las niñas y adolescentes, quienes, no se escapan de estar expuestas a la persecución penal en calidad de infractoras ${ }^{(11)} y$, además, están expuestas a los embarazos forzados por violación y, por ende, a la violencia institucional en los servicios de salud.

\section{Violación sexual y embarazo infantil}

Como hemos visto, siguiendo los postulados de Facio y Cook, el Derecho ha sido construido invisibilizando las necesidades, tiempos y experiencias de las mujeres. Esta miopía de género se ve reflejada de manera paradigmática en la débil respuesta estatal para enfrentar la violación sexual y prevenir sus consecuencias.

La violación sexual es una de las formas más crueles de violencia de género, que histórica y estructuralmente ha afectado a las mujeres, vulnerando su dignidad, libertad e integridad sexual. Desde un punto de vista de la salud mental, representa uno de los traumas más severos que se pueden experimentar (Rondón, 2015, pág. 22). Las razones que originan esta forma de violencia son múltiples y entre ellas destacan los imaginarios machistas que sostienen ideas y conductas de apropiación y dominio sobre el cuerpo de las mujeres ${ }^{(12)}$.

En el Perú, la prevalencia de denuncias por este delito es alarmante y es expresión de lo que desde las teorías feministas se ha denominado la cultura de la violación ${ }^{(13)}$ : En el 2017, el Observatorio de la Criminalidad del Ministerio Público registró 25068 denuncias por violación; alertando que se presentaban al menos 70 de éstas cada día ${ }^{(14)}$. En el 2019, más de 7000 casos de violencia sexual fueron atendidos por los Centros de Emergencia Mujer, el $65 \%$ de víctimas eran menores de edad.

Dado el intenso sufrimiento, la humillación y la intencionalidad de dañar con que esta agresión suele producirse en determinados contextos, en el Derecho Internacional de los Derechos Humanos se ha llegado a equiparar la violación con una forma de tortura contra

(9) CAT/C/PER/CO/4

(10) En virtud al artículo 57 del Código Penal, el juez puede suspender la ejecución de la pena cuando la condena se refiera a una pena privativa de libertad menor de 04 años y se cumplan los requisitos establecidos en el dispositivo penal.

(11) El artículo 183 del Código de Niños, niñas y adolescentes señala: "Se considera adolescente infractor a aquél cuya responsabilidad ha sido determinada como autor o partícipe de un hecho punible tipificado como delito o falta en la ley penal".

(12) Una política educativa con enfoque de igualdad de género puede ayudar a transformar y erradicar estas estructuras.

(13) Es un término que en sociología y diversos estudios feministas ha sido utilizado para denunciar el estado de normalización y justificación que sostiene y reproduce sistemáticamente la violencia sexual contra las mujeres en una sociedad.

(14) Fuente: https://www.mpfn.gob.pe/?K=504\&id=5939 
las mujeres, en los términos del artículo 5.2 de la Convención Americana de Derechos Humanos y 2 de la Convención Interamericana para Prevenir y Sancionar la Tortura(15); así se pronunció la Corte Interamericana de Derechos Humanos, en la sentencia Fernández Ortega y otros vs. México.

En nuestra legislación, los tipos penales y las políticas públicas para sancionar y atender esta forma de violencia han evolucionado en el tiempo. Actualmente, queda muy poco de la normativa inicialmente establecida con la entrada en vigencia del Código Penal de $1991^{(16)}$, cuyo gran aporte fue reconocer a la libertad y la indemnidad sexual como bienes jurídicos protegidos en los delitos sexuales, superando así la concepción del honor como bien jurídico, tal como establecía la legislación previa (Silva, 2014, pág. 61).

Destacamos el papel fundamental de los Acuerdos Plenarios aprobados por la Corte Suprema de la República, vinculados a la relevancia de la declaración de la víctima y sus garantías de certeza ( $\left.N^{\circ} 2-2005 / C J-116\right)$, la valoración de la prueba en los delitos sexuales ( $\left.\mathrm{N}^{\circ} 1-2011 / \mathrm{CJ}-116\right)$ y la justicia de género con perspectiva intercultural ( $N^{\circ} 1-2015 /$ CJ-116), ya que optimizaron los criterios jurisprudenciales y procesales para investigar, juzgar y sancionar estos delitos, en cumplimiento a los estándares internacionales sobre derechos humanos.

También destacamos, la aprobación de políticas públicas con vocación de integralidad y enfoque de intersección como la Ley 30364- Ley para prevenir, sancionar y erradicar la violencia contra las mujeres y los integrantes del grupo familiar, que reconoce derechos para la protección de las víctimas, tales como la entrevista única con calidad de prueba preconstituida (artículo 11 de su Reglamento) y la atención integral en salud sexual y reproductiva como el acceso al llamado "kit de emergencia" (artículo 59 de su Reglamento).

La última reforma establecida con la Ley $30838^{(17)}$ ha generado importantes avances en el plano normativo, entre estos, que ahora los delitos sexuales son imprescriptibles, lo cual introduce la perspectiva de género en la compresión de la acción y persecución penal de estos crímenes, considerando los tiempos propios que atraviesan las mujeres para denunciar, mucho más en el caso de niñas y adolescentes, por la situación de vulnerabilidad que suelen enfrentar. Asimismo, esta ley modifica con mayor precisión la redacción de tipos penales, colocando al consentimiento como un elemento normativo clave en estos delitos y precisando, además, que la violencia ejercida para derrotar dicho consentimiento puede ser física, psicológica o involucrar cualquier entorno de coacción. En materia procesal, determinó la no terminación anticipada o reducción de la pena en los procesos seguidos por estos delitos.

También estableció el incremento de las penas contra agresores, para delitos como el tipo base de violación sexual (artículo 170) (18), violación sexual a persona en incapacidad de resistir (artículo 171) ${ }^{(19)}$ y el delito de abuso sexual hacia menores de catorce años (artículo 173), que ahora se sanciona en todos los casos con cadena perpetua. Consideramos que si bien, en el seno de un Estado Constitucional de Derecho, es importante fijar sanciones proporcionales a los daños cometidos contra los bienes jurídicos protegidos, estas sanciones, por más drásticas que sean, son un espejismo en tanto no se garantice la debida diligencia en la investigación, juzgamiento y sanción de estos casos, que es una obligación internacional del Estado de acuerdo al artículo 7 de la Convención Belem Do Pará. Al respecto, preocupa la realidad, todavía no erradicada, que fue reconocida en la parte introductoria del Acuerdo Plenario 1-2011: el $90 \%$ de denuncias por violación sexual quedan impunes, es decir, sin reparación para las víctimas ni sanciones hacia los agresores.

(15) Caso Fernández Ortega y otros v. México, excepción preliminar, fondo, reparaciones y costas, sentencia de 30 de agosto de 2010; considerando 127 y 128. Para la Corte Interamericana de Derechos Humanos, una violación sexual constituye un acto de tortura cuando el maltrato cumple con los siguientes requisitos: i) es intencional; ii) causa severos sufrimientos físicos o mentales, y iii) se comete con determinado fin o propósito.

(16) Ejemplo, el tipo penal base de violación sexual, establecido con la entrada en vigencia del Código Penal de 1991 era el siguiente: "Artículo 170.- El que, con violencia o grave amenaza, obliga a una persona a practicar el acto sexual u otro análogo, será reprimido con pena privativa de libertad no menor de tres ni mayor de seis años. Si la violación se realiza a mano armada y por dos o más sujetos, la pena será no menor de cuatro ni mayor de doce años".

(17) Ley 30838 - Ley que modifica el Código Penal y el Código de Ejecución Penal para fortalecer la prevención y sanción de los delitos contra la libertad, fue promulgada en agosto del año 2018.

(18) Con la Ley 30838 , se ha incrementado la pena privativa de libertad en este delito "no menor de seis ni mayor de ocho años" a "no menor de 14 ni mayor de 20 años".

(19) Con la Ley 30838 , se ha incrementado la pena privativa de libertad en este delito "no menor de diez ni mayor de quince años" a "no menor de 20 ni mayor de 26 años". 
En ese sentido, la vocación meramente represiva del Derecho Penal, si bien puede aparentar mayor protección legal a los bienes jurídicos en riesgo, debe ser superada por un efectivo acceso a la justicia para las víctimas que denuncian ${ }^{(20)} y$ el fortalecimiento y la implementación adecuada de políticas de prevención de la violencia sexual, con énfasis en la protección de la infancia, población que se encuentra especialmente vulnerable a esta forma de violencia y sus consecuencias. Por ello, no es de extrañar que la mayoría de modificatorias hechas al capítulo de delitos sexuales en las últimas décadas se relacione al incremento de las sanciones penales contra agresores de menores de edad (Llaja y Silva, 2016, pág. 24).

Efectivamente, la edad es un factor que coloca a las mujeres en especial situación de peligro frente a esta agresión, como ha reconocido el Comité de Derechos del Niño de las Naciones Unidas ${ }^{(21)}$. Así lo demuestran reportes mundiales, regionales y nacionales, en los que las niñas y adolescentes son las principales víctimas en las denuncias registradas por este crimen, pese a que su Interés Superior y seguridad son principios que debieran ser garantizados con prioridad, por todos los Estados partes, en cumplimiento de la Convención de los Derechos del Niño. Este tratado fue ratificado por nuestro país en 1990 y, como profundizaremos en el siguiente acápite, marcó un trascendental cambio de enfoque jurídico en los derechos de la infancia.

En virtud al artículo 19 de la Convención Americana, existe la obligación de proteger de manera reforzada los derechos de las niñas y adolescentes por parte del Estado peruano; sin embargo, son ellas las principales afectadas por la violencia sexual, incluso en espacios que deberían ser seguros para su desarrollo: De acuerdo al Observatorio de la Criminalidad del Ministerio Público, la violencia sexual contra menores de edad ocurre en entornos cercanos y de confianza. En el $78 \%$ de los casos, los agresores fueron familiares de las víctimas ${ }^{(22)}$, lo cual explica el porqué las mujeres tardan en denunciar; sus victimarios conviven con ellas, suelen ser sus padres, tíos, hermanos, docentes o personas del entorno de confianza, lo cual aminora las posibilidades de reconocer y salir pronto de los círculos de violencia.

Por lo señalado, consideramos que los grandes desafíos para la protección de la infancia se centran en: (i) la prevención multisectorial de la violencia basada en género, (ii) el acceso oportuno y efectivo a la justicia sin revictimización ni impunidad, así como (iii) la atención integral de las menores de edad víctimas de la violencia sexual y sus consecuencias. Estos indicadores forman parte de los objetivos del Estado, según la Política Nacional de Igualdad de Género, aprobada mediante Decreto Supremo 0082019-MIMP.

Respecto al punto (i), existen políticas que tienen como objetivo la prevención de la violencia de género, como el Currículo Nacional de Educación Básica, Los Lineamientos para una Educación Sexual Integral, el Plan Nacional de Acción por la Infancia y la Adolescencia 2016-2021 y el Plan Multisectorial de prevención del embarazo adolescente; la adecuada implementación de estos instrumentos sigue siendo un pendiente urgente de nuestro Estado, según reporta continuamente la Defensoría del Pueblo y organizaciones de sociedad civil.

Sobre el punto (ii), desde el año 2015 está vigente la Ley 30364 que, junto a su Reglamento, tiene por objeto (artículo 1) prevenir, erradicar y sancionar toda forma de violencia producida en el ámbito público o privado contra las mujeres por su condición de tales y los integrantes del grupo familiar. Esta ley se enmarca en los mandatos de la Convención Belem Do Para y responde a la obligación estatal de debida diligencia reforzada, que incluye la adopción de "un adecuado marco jurídico de protección, con una aplicación efectiva del mismo y con políticas de prevención y prácticas que permitan actuar de una manera eficaz"(23). Si bien el Estado ha cumplido con la emisión de una normativa integral en ese sentido, es urgente su implementación efectiva.

Sobre el punto (iii), se cuenta con normativa sobre atención integral de niñas y adolescentes víctimas de violencia sexual, como dispone la Ley 30364, que establece asistencia integral psicológica y médica para las víctimas, así como "(...) equipos de emergencia para casos de violación

(20) En tiempos de discusión pública sobre una necesaria reforma institucional en el sistema de justicia peruano, es necesario analizar cuán vigente es el contexto reconocido en la parte introductoria del Acuerdo Plenario 1-2011: Que el 90\% de denuncias por violación sexual quedan impunes.

(21) Comité de los Derechos del Niño, Observación General 13: Derecho del niño a no ser objeto de ninguna forma de violencia, supra, párr. 72.f).

(22) Fuente: Observatorio de la Criminalidad del Ministerio Público, año 2017. Disponible en: https://www.mpfn.gob.pe/?K=505\&id=5461

(23) Corte Interamericana de Derechos Humanos. Caso González y otras ("Campo Algodonero") vs. México. Sentencia de 16 de noviembre de 2009. Párr. 258. 
sexual" e información "sobre el derecho a recibir tratamiento frente a infecciones de transmisión sexual, antiretrovirales, anticonceptivo oral de emergencia y otros, los cuales se suministran a la víctima, previo consentimiento informado." (Artículo 59.1). Sin embargo, poco se ha avanzado en relación a una de las consecuencias más graves de la violencia sexual infantil, históricamente invisibilizada, pero cada vez más visible.

Como señala el Mecanismo de Seguimiento de la Convención de Belém Do Pará (MESECVI), en los últimos años la gravedad de la violencia sexual contra las niñas durante la adolescencia temprana se ha hecho más notoria dada la amplia visibilidad que se ha dado en la región de casos de niñas embarazadas producto de la violencia sexual, que son obligadas a continuar con su embarazo por diversas razones, entre las que destacan "las prohibiciones legales de la interrupción del embarazo, la desinformación sobre estos hechos, la existencia de legislación que perpetúa los estereotipos de género y la ausencia de protocolos de actuación en los casos donde el aborto es legal" (MESECVI, 2016, pág. 7).

América Latina y El Caribe enfrenta de manera particular esta problemática, al ser la única región en el mundo donde los partos en niñas menores de 15 años van en aumento, y la segunda región con mayor número de embarazos en adolescentes entre 15 y 19 años (UNFPA, UNICEF, OPS y OMS, 2018, pág. 15).

Si bien tradicionalmente el embarazo en niñas menores de 14 años se ha incluido dentro del embarazo adolescente (14 a 18 años), son dos realidades distintas. Como evidenció el Comité de América Latina y el Caribe para la Defensa de los Derechos de las Mujeres (CLADEM), a través del Informe Regional "Niñas Madres. Embarazo y maternidad infantil forzada en América Latina y el Caribe" (2016b), el embarazo en adolescentes mayores de 14 años tiene como principal origen una iniciación sexual temprana, a la que se suman deficiencias en el acceso a métodos anticonceptivos, educación sexual integral e información.

El embarazo infantil, por su parte, tiene como principal origen el abuso sexual, sumándose a ello el que muchas legislaciones establecen que la edad del consentimiento sexual de las adolescentes inicia a los 14 años, como ocurre en el Perú. Por tanto, estos embarazos, al ser evidencia de una relación sexual con una niña, por regla general, deben considerarse como producto de una agresión sexual.

EI CLADEM ha avanzado en la conceptualización de una categoría entorno a esta problemática, denominándola Embarazo Infantil Forzado, que es el embarazo en niñas, producto de un abuso sexual, a quienes se les impide u obstaculiza interrumpir la gestación (CLADEM, 2016b, pág. 9).

Esta categoría apunta a remirar el embarazo en niñas, a quienes se les niega u obstaculiza el derecho a interrumpir la gestación, en referencia a otra categoría jurídica presente en el derecho penal internacional: el embarazo forzado(24). La construcción de una jurisprudencia y doctrina que desarrolle, contextualice y fundamente como categoría penal específica al Embarazo Infantil Forzado es un desafío todavía pendiente y por explorarse, como en su momento lo fue el feminicidio. Lo cierto es que esta problemática existe históricamente y en países como Perú, donde el aborto se penaliza de forma casi absoluta, y alcanza cifras dramáticas.

Según data levantada por la organización feminista CLADEM- Perú, durante el año 2018 se registraron 2344 nacimientos en los que se inscribieron como madres a niñas de entre 7 a 14 años. De otro lado, desde la labor de monitoreo que realiza el Centro de la Mujer Peruana Flora Tristán se pudo obtener información sobre el número de partos en niñas menores de 15 años reportados por el Ministerio de Salud en los últimos tres años. En el 2016, se reportaron 1162 niñas menores de 15 años que tuvieron partos; el 2017 fueron 1312 niñas y el 2018 fueron 1420 . Por lo que, entre el 2016 y 2018, son 3894 niñas ${ }^{(25)}$ que tuvieron partos en todo el territorio nacional. Es decir, aproximadamente 4 niñas cada día.

Teniendo en cuenta la edad del consentimiento sexual en adolescentes, se desprende que un gran porcentaje de los embarazos y partos reportados fueron resultado del abuso sexual, que el Estado fracasó en prevenir y suele fracasar en investigar y sancionar, incumpliendo con ello sus obligaciones de debida diligencia.

Como veremos a continuación, la conjunción entre el embarazo infantil y la penalización del aborto en casos de violación puede dar origen a una violación diferenciada a los derechos humanos de las niñas, que

(24) Tipificado en el artículo 7 del Estatuto de Roma, sobre crímenes de lesa humanidad.

(25) Data obtenida por el Centro de la Mujer Peruana Flora Tristán, mediante acceso a la información pública solicitada al Ministerio de Salud. 
abona en la demanda por la despenalización de la interrupción del embarazo por esta causa.

\section{Embarazo infantil y penalización del aborto como formas de violación estructural a los Derechos Humanos de las niñas}

El Comité de Derechos Económicos, Sociales y Culturales, que supervisa la implementación del Pacto Internacional de Derechos Económicos, Sociales y Culturales (PIDESC), en su Observación General 20, ha señalado que un supuesto de discriminación directa se configura cuando "(...) un individuo recibe un trato menos favorable que otro en situación similar por alguna causa relacionada con uno de los motivos prohibidos de discriminación".

Para el Derecho Internacional de los Derechos Humanos es un amplio consenso que el sexo es un motivo prohibido de discriminación y, en ese sentido, es claro que la prohibición penal del aborto en casos de violación sexual es una forma de discriminación directa hacia las mujeres, pues esta normativa, en base a estereotipos de género que solo se imponen sobre las mujeres, les impide el acceso a los servicios de salud y restringe el respeto a su autonomía reproductiva. (Facio, 2009, pág. 106).

Ahora, si bien sobre la base de este motivo prohibido de discriminación, podemos advertir que la penalización del aborto vulnera los derechos humanos de todo el colectivo de mujeres, tiene un impacto diferenciado entre las mismas, según las condiciones de vida y las discriminaciones específicas que cruzan a la diversidad de mujeres.

Esta aproximación hacia la problemática del aborto es posible a partir de una mirada interseccional, que permita identificar "cuál es la mujer que se está contemplando como 'el otro' del paradigma de ser humano que es hombre/varón y desde ahí analizar cuál o cuáles son sus efectos en las mujeres de distintos sectores, clases, razas, etnias, creencias, orientaciones sexuales, etc." (Facio, 2009, pág. 182). Este enfoque de interseccionalidad cuenta con asidero legal en leyes como la Ley 30364, que en su artículo 5 reconoce que “(...) la experiencia de que las mujeres tienen de la violencia se ve influida por factores e identidades como su etnia, color, religión; opinión política o de otro tipo (...)".

Como señalan diversas organizaciones de sociedad civil, la problemática del embarazo infantil no se visibilizará ni enfrentará adecuadamente, sino por medio del enfoque de derechos humanos e interseccionalidad (CLADEM, 2016b, pág. 15), que permita identificar el impacto diferenciado de la penalización del aborto y el continuum de vulneraciones a los derechos de las niñas, en quienes convergen discriminaciones múltiples, entre ellas por el género y la edad.
Al respecto, nos parece útil recurrir a las metodologías feministas de análisis del fenómeno legal, que, frente a problemas jurídicos, como la penalización del aborto, aportan en la contextualización tanto de los hechos como del derecho, generando que los casos se evalúen en atención a las realidades particulares de los/las afectados/as en el caso concreto, en este caso, las niñas (Ramírez, 2013, pág. 142).

La metodología que usaremos es la llamada pregunta por la mujer, propuesta por la profesora estadounidense Katherine Bartlett. Consiste en formularnos la pregunta de cómo una determinada norma, aparentemente neutra, impacta en los derechos de las mujeres, y así examinar "cómo los estándares y conceptos legales existentes podrían poner en desventaja a las mujeres" (Bartlett, 1990, pág. 32). Aunque parezca un ejercicio sencillo, frecuentemente tanto legisladores como operadores de justicia omiten formularse esta interrogante al momento de diseñar, debatir, aprobar $\mathrm{u}$ adoptar leyes o decisiones jurídicas, invisibilizando así a las mujeres. Esta metodología también incluye un enfoque de interseccionalidad, en tanto "el análisis de género no debe realizarse aparte sino dentro de los contextos de múltiples identidades", es decir, "para hablar de las mujeres se debe nombrar explícitamente a qué mujeres se alude" (Bartlett, 1990, pág. 49).

En ese sentido, en relación a la penalización del aborto en casos de violación sexual, la pregunta que proponemos es la pregunta por las niñas, quienes han sido frecuentemente ignoradas en los debates políticos y jurídicos sobre el tema, y todos los que tengan que ver con derechos sexuales y reproductivos: ¿Sufren ellas una vulneración diferenciada en sus derechos? ¿De qué manera se refleja y cómo se traduce en términos de obligaciones estatales? Aunque la respuesta parezca obvia, hay toda una argumentación anclada en derechos y principios pendiente de posicionar en el debate público y jurídico.

A priori, nos parece importante partir por reconocer la situación de desigualdad y especial vulnerabilidad en la que se encuentran las niñas. El Tribunal Constitucional, con motivo de una sentencia del año 2017, que 
se pronunció sobre el acceso al derecho a la educación en zonas rurales, ha reconocido la existencia de una problemática histórica de discriminación en el ejercicio de los derechos de las mujeres, especialmente "de aquellas que se encuentran en situación de vulnerabilidad, como es el caso de las niñas y adolescentes (...)"(26). Esta situación de vulnerabilidad está marcada por discriminaciones por motivo de género, como la violencia sexual y los embarazos forzados, que con frecuencia son minimizadas, pues dada su minoría de edad, las niñas son consideradas como un mero objeto de tutela y no de derechos (MESECVI).

Frente a esta situación de discriminación estructural hacia las niñas, el Derecho Internacional de los Derechos Humanos ha desarrollado un corpus juris de protección a la infancia, que ha permitido definir los alcances de los derechos de las niñas, niños y adolescentes, así como las obligaciones de los Estados. Este corpus juris ha sido aplicado por tribunales supranacionales como la Corte Interamericana ${ }^{(27)}$ y está integrado por tratados internacionales como la Convención Americana de Derechos Humanos, y otros instrumentos creados para una protección integral de la niñez y las mujeres durante todo su ciclo de vida: la Convención sobre los Derechos del Niño (1989) y la Convención Interamericana para prevenir, sancionar y erradicar la violencia contra las mujeres (1994) son tratados internacionales ratificados por el Perú que, al versar sobre derechos humanos, detentan rango constitucional en nuestro ordenamiento jurídico y sirven para interpretar el contenido de los derechos incluidos en nuestra Constitución ${ }^{(28)}$.

La Convención sobre los Derechos del Niño (y Niña), fue aprobado en 1989, durante un proceso conocido como especificación de los Derechos Humanos, caracterizado por la creación de instrumentos y tratados internacionales que garantizan derechos a ciertos grupos en situación de vulnerabilidad (Bobbio, 1991, pág. 110). Este tratado sentó un cambio de enfoque integral sobre la infancia, reconociendo a las niñas, niños y adolescentes como titulares de derechos humanos y no objetos de simple tutela y protección, como postulaba la denominada doctrina de la situación irregular (Ramírez, 2018a, pág. 91). Por su parte, la Convención de Belém do Pará, que aborda de forma integral la violencia contra las mujeres, establece que los Estados Partes tendrán especialmente en cuenta la situación de vulnerabilidad a la violencia que pueda sufrir la mujer en razón, entre otras, de su minoría de edad (artículo 9).

El embarazo infantil forzado y la prohibición a la interrupción del embarazo por esta causal viola el corpus juris de protección internacional de los derechos de la niña y las bases constitucionales acordes al Interés Superior del Niño(a), reconocido como un principio de consideración primordial que los Estados deben considerar en todas las medidas adoptadas, concernientes a los derechos de las niñas ${ }^{(29)}$.

En primer lugar, la penalización del aborto se traduce en una prohibición que impide que las niñas y mujeres puedan ser atendidas en los servicios de salud para interrumpir una gestación originada por una agresión sexual de manera segura. De hecho, el médico que atienda a una mujer con indicios de aborto punible está obligado a reportar los hechos a las autoridades, según dispone el artículo 30 de la Ley 26842, Ley General de Salud( ${ }^{(30)}$.

En consecuencia, esta norma restringe a las niñas el acceso a los servicios de salud para interrumpir el embarazo, lo cual contraviene los estándares establecidos por el Comité de los Derechos del Niño, que en su Observación General 15 - Sobre el Derecho del niño al disfrute del más alto nivel posible de salud, recomendó a los Estados partes desplegar esfuerzos para que ninguna niña o niño se vea privado de su derecho al disfrute de los servicios sanitarios; en relación al aborto, el Comité se pronunció señalando: "En vista de las altas tasas mundiales de embarazo en la adolescencia y de los consiguientes riesgos de morbilidad y mortalidad, los Estados han de velar por que los sistemas y servicios sanitarios puedan atender las necesidades de los adolescentes en materia de salud sexual y reproductiva, incluso mediante servicios de

(26) STC EXP N..$^{\circ}$ 00853-2015-PA Fundamento 31.

(27) Como en el caso V.R.P., V.P.C. ${ }^{*}$ y otros vs. Nicaragua, Sentencia del 8 de marzo de 2018 (Excepciones Preliminares, Fondo, Reparaciones y Costas).

(28) IV Disposición Final y Transitoria de la Constitución. "Las normas relativas a los derechos y a las libertades que la Constitución reconoce se interpretan de conformidad con la Declaración Universal de Derechos Humanos y con los tratados y acuerdos internacionales sobre las mismas materias ratificados por el Perú".

(29) Expediente No. 02079-2009-PHC/TC (Tribunal Constitucional [Perú], 9 de setiembre de 2010). Fundamento 8.

(30) Artículo 30.- El médico que brinda atención médica a una persona herida por arma blanca, herida de bala, accidente de tránsito o por causa de otro tipo de violencia que constituya delito perseguible de oficio o cuando existan indicios de aborto criminal, está obligado a poner el hecho en conocimiento de la autoridad competente. 
planificación familiar y aborto en condiciones de seguridad. Los Estados deben procurar que las niñas puedan tomar decisiones autónomas y fundamentadas sobre su salud reproductiva".

De otro lado, contraviene la Recomendación General 24 del Comité CEDAW, que establece que "la negativa de un Estado Parte a prever la prestación de determinados servicios de salud reproductiva a la mujer en condiciones legales resulta discriminatoria". En el caso de las niñas, esta discriminación supone la imposición de un estereotipo que le asigna una función reproductiva a su temprana edad.

La prohibición penal de la interrupción del embarazo en casos de violación, determina que se imponga a las niñas y mujeres un curso de acción determinado: ser madre sí o sí, pues una decisión distinta sería ilegal en tanto abortar está prohibido por la norma penal (Díaz \& Ramírez, 2013, pág. 11). En la práctica, se toman dos caminos: O interrumpir el aborto en condiciones clandestinas o continuar el embarazo y asumir una maternidad no deseada y forzada por violación.

En el caso de las adolescentes menores de 14 años, las cifras demuestran que están sistemáticamente expuestas a esta última realidad, y es que el embarazo infantil forzado se produce en contextos complejos de vulnerabilidad, donde los principales agresores son personas del entorno más cercano a la víctima, lo cual tiende a hacer más difícil que ellas puedan denunciar la agresión sufrida y, en consecuencia, recibir el acompañamiento correspondiente para la protección de su salud. La mayoría de casos de embarazo infantil, son reportados cuando la gestación se encuentra bastante avanzada. Sobre esta situación, ha alertado la Defensoría del Pueblo(31).

Como apunta la abogada Susana Chiarotti, obligar a una niña que no ha terminado de crecer a llevar a término un embarazo, ser madre y criar a un bebé debe ser considerado tortura o trato cruel, inhumano y degradante, en los términos de la Convención de la Tortura y otros tratos o penas crueles, inhumanos o degradantes y del Pacto Internacional sobre Derechos Civiles y Políticos (CLADEM, 2017, pág. 8). A continuación, examinamos la vulneración a los derechos de las niñas que nos permitirá corroborarlo.

Primero, el derecho a la integridad. Un embarazo a temprana edad representa un riesgo muy alto de muerte por embarazo y parto. Pueden ocurrir complicaciones durante este proceso, ya que las niñas tienen cuatro veces mayores riesgos de morir durante el parto que una mujer adulta, según la Organización Mundial de la Salud. Este riesgo se debe a que las niñas menores de 14 años, aunque hayan menstruado, su cuerpo no está preparado para atravesar un embarazo y menos aún un parto; el piso pélvico no está totalmente desarrollado. Esto las expone a casos de desnutrición, partos prematuros, malformaciones y debilidad ósea (CLADEM, 2017, pág. 15).

Segundo, derecho a la salud mental. El Comité de los Derechos del Niño y la Niña ${ }^{(32)}$ ha alertado sobre el mayor riesgo que tienen las niñas embarazadas de experimentar síntomas depresivos y desarrollar pensamientos suicidas en comparación con las mujeres adultas en el mismo estado. Los daños emocionales incrementan cuando el abuso sexual fue incestuoso. Además, un embarazo forzado por violencia sexual frecuentemente genera depresión postparto, estrés post traumático y alteraciones de la memoria, así como generación de ideas suicidas (Rondón, 2015, pág. 31).

Otro de los derechos afectados son la de educación y el proyecto de vida, ya que muchas niñas que quedan embarazadas tienen que abandonar la escuela y están expuestas a vivir en la pobreza (CLADEM, 2016b, pág. 28).

Es evidente, entonces, que la penalización del aborto en casos de violación sexual expone a las niñas a embarazos que las revictimizan, (i) generan sufrimiento constante, (ii) negación de autonomía progresiva y vulneración de su salud, así como (iii) afectación a sus derechos a la educación y proyecto de vida. Esta grave vulneración de derechos, no justifica la protección absoluta del feto o embrión en detrimento de los derechos de las niñas. Que el Estado penalice el aborto por esta causal, a pesar de los graves daños que ocasiona, atenta manifiestamente contra el Interés Superior de la Infancia.

Sostenemos que nos encontramos frente a un continuum de violencia de género, que no empieza con la prohibición del aborto, sino con la comisión un delito de abuso sexual que el Estado falló en prevenir. Este ciclo de violencias prosigue durante todo el periodo de embarazo y luego del parto, reflejándose en la impunidad en la que quedan muchos

(31) Disponible en: https://www.defensoria.gob.pe/constatamos-que-servicios-de-salud-vulneraron-los-derechos-de-adolescenteembarazada-tras-violacion/

(32) Comité de los Derechos del Niño. Comentario General No. 4: Salud adolescente y desarrollo. U.N. Doc. CRC/GC/ 2003/4, 27 (julio 2003). 
de los casos y en la maternidad no deseada que la niña debe asumir interrumpiendo su desarrollo de vida. Se incumple así la obligación de debida diligencia del Estado para prevenir, investigar y sancionar los actos de violencia contra las mujeres, reconocido en el artículo 7 de la Convención de Belén do Para, la cual, en el caso específico de las niñas, es un deber reforzado y más estricto, según el artículo 19 de la Convención Americana y en disposiciones de la Convención sobre Derechos del Niño.

Cabe anotar, que mientras el aborto por violación no se despenalice, es legítimo que se demande el acceso al protocolo de aborto terapéutico para proteger la salud física y mental de las niñas gestantes producto de esta agresión ${ }^{(33)}$. Como vimos en el primer acápite, este el único tipo de aborto no punible en el país y es aplicable en los casos en los que la vida o salud de la mujer/niña gestante esté en riesgo o en inminente peligro.

Que las niñas accedan al aborto terapéutico para proteger su salud física y mental es un desafío, como ha constatado CLADEM Perú(34). Esta organización identificó la persistencia de barreras como la interpretación restrictiva que los operadores del sistema sanitario realizan sobre la salud de las niñas. No se comprende a la afectación psicológica, producto de la violación sexual y el embarazo forzado, como un daño grave a la salud integral, que amerite la interrupción terapéutica.

Asimismo, el desconocimiento del protocolo por parte de funcionarios de los servicios de salud, así como las limitaciones propias de este instrumento, ya que señala que el procedimiento sanitario solo es atendible antes de las 22 semanas de gestación, lo cual constituye un obstáculo, pues la mayoría de casos de embarazos infantiles forzados son identificados en estadios gestacionales avanzados o en el límite de las 22 semanas.

Al respecto, en la memoria de los derechos reproductivos y la igualdad, existen dos casos emblemáticos en los que se declaró responsable al Estado peruano por no garantizar el aborto terapéutico a menores de edad, debido a una interpretación restrictiva del derecho a la salud mental (Caso K.L vs Perú( $\left.{ }^{35}\right)$ y a la no eliminación de patrones discriminatorios en los servicios de salud, así como la ausencia de un procedimiento idóneo para su acceso efectivo (caso L.C. vs. Perú( ${ }^{(36)}$ ).

El caso L.C. se trató de una niña de 13 años que quedó embarazada producto de repetidas violaciones sexuales que sufría por parte de un hombre mayor; debido a esta situación, intentó suicidarse saltando al vacío desde el techo de una casa, sufrió una lesión en la médula espinal. Fue trasladada a un hospital público donde se le recomendó una intervención quirúrgica para evitar que se consolidara el daño en su columna, pero al advertir su embarazo los médicos se negaron a practicarle dicha cirugía para no generar daños en el feto, negándole además su solicitud de aborto terapéutico.

En el año 2011, el Comité para la Eliminación de Todas las Formas de Discriminación contra la Mujer (CEDAW) se pronunció sobre este caso, determinando que el Estado peruano era responsable internacionalmente por vulnerar la garantía de pleno goce y ejercicio de los derechos fundamentales de L.C. y su acceso a la justicia, en tanto en aquellos años no existía un protocolo para la interrupción legal del embarazo. Además de vulnerar su derecho a la igualdad y no discriminación en la atención médica, por cuanto se le había impedido acceder al aborto terapéutico debido a estereotipos y patrones socioculturales que privilegiaron el desarrollo del feto, en detrimento de su salud. En ese extremo el Comité señaló: "la negativa de un Estado Parte a prever la prestación de determinados servicios de salud reproductiva a la mujer en condiciones legales resulta discriminatoria", ya que es "deber de los Estados Partes de asegurar, en condiciones de igualdad entre hombres y mujeres, el acceso a los servicios de atención médica, la información y la educación".

Respecto a la criminalización del aborto en casos de violación, el Comité consideró que el hecho de que "el Estado parte no protegiera los derechos reproductivos de la mujer ni promulgara leyes para reconocer el aborto por causa de abuso sexual o violación contribuyó a la situación en que se encuentra L.C.". Consecuentemente,

(33) Guía Técnica Nacional para la Estandarización del Procedimiento de la Atención Integral de la Gestante en la Interrupción Voluntaria por Indicación Terapéutica del embarazo.

(34) A través de la ejecución de un proyecto social denominado "Vigilancia e incidencia para la prevención, atención y sanción del Embarazo Infantil Forzado", el mismo que se viene desplegando desde el año 2018, en distintas regiones del país.

(35) Comité de Derechos Humanos. CCPR/C/85/D/1153/2003, dictamen aprobado en octubre de 2005. Recuperado de: http://www. mimdes.gob.pe/files/DIRECCIONES/DGM/dictamen_caso_KL.pdf

(36) Comité para la eliminación de la discriminación contra la mujer. CEDAW/ C/50/D/22/2009, dictamen aprobado el 17 de octubre de 2011. Disponible en: http://www2. ohchr.org/english/law/docs/CEDAW-C-50-D-22-2009_sp.pdf 
entre las recomendaciones dadas por el Comité al Estado Peruano estuvo, así como garantizar las condiciones para la implementación del aborto terapéutico, que se despenalizara el aborto en casos de violación sexual.

\section{Conclusiones}

Como hemos visto, el artículo 120 del Código Penal, que prohíbe el aborto en casos de violación sexual, es una norma creada desde una perspectiva masculina, que genera una grave vulneración a los derechos humanos de las mujeres $\mathrm{y}$, por tanto, desde un punto de vista constitucional, no se justifica su permanencia en el Código Penal; en esa línea, se han pronunciados los Comités Monitores de tratados de la Naciones Unidas, que han recomendado que se despenalice la interrupción del embarazo por esta causa y se permita el acceso a las mujeres a los servicios de salud.

La penalización del aborto por esta causal vulnera los derechos de las mujeres, al ser una norma que impone un estereotipo de género que recae solamente en las personas de sexo femenino, vinculado a la maternidad como destino irrenunciable que se debe asumir. Sin embargo, esta prohibición genera un impacto diferenciado en las niñas menores de 14 años, quienes están expuestas a la violencia sexual y los embarazos forzados que las someten a un continuum de vulneraciones a sus derechos humanos, incumpliéndose así los estándares internacionales de protección a la infancia, que ameritan una debida diligencia reforzada, en el marco de los tratados internacionales suscritos por el Perú, que cuentan con rango constitucional en nuestro ordenamiento jurídico.

El embarazo infantil forzado está empezando a visibilizarse como una problemática autónoma de derechos humanos, que afecta a las niñas menores de 14 años, quienes son sujetos de derecho con protección especial, pero que paradójicamente se encuentran más expuestas a los abusos sexuales que el Estado no logra prevenir efectivamente. Aproximarse a esta problemática amerita contar con un enfoque de interseccionalidad, que permita identificar las vulneraciones de derechos cruzadas por la discriminación en base al género y la edad.

Enfrentar la problemática del embarazo infantil demanda una respuesta integral del Estado Peruano, que apunte a la prevención de la violencia de género, la no revictimización de las niñas en el sistema de justicia y la no impunidad de los agresores. Despenalizar el aborto por causal de violación sexual es un pendiente urgente, en cumplimiento de los estándares internacionales sobre derechos humanos y las recomendaciones dadas por los Comités de seguimiento a los Tratados Internacionales, que han adoptado una postura sensible a la problemática de género.

\section{Referencias bibliográficas}

Bartlett, Katharine (1990). Métodos Jurídicos Feministas. En M. Fernández \& F. Morales (Coord.). Métodos Feministas en el Derecho. Aproximaciones críticas a la jurisprudencia peruana (2011). Lima: Palestra Editores.

Bobbio, Norberto (1991). El tiempo de los derechos. (R. Roig, trad) Madrid: Editorial Sistema. Recuperado de http://culturadh.org/ue/wp-content/ files_mf/144977835110.pdf

Cook, Rebecca \& Cusack, Simone (2009). Estereotipos de Género. Perspectivas Legales Trasnacionales. (A. Parra, trad.) Bogotá: Profamilia.

Comité de América Latina y el Caribe para la Defensa de los Derechos de las Mujeres (CLADEM) (2016a). Acceso a la justicia, niñas madres y situación de defensoras de derechos humanos. Informe Regional Alterno al Comité de Expertas (CEVI) Tercera Ronda de Evaluación Multilateral del Mecanismo de Seguimiento de la Convención de Belém do Pará (MESECVI). Sao Paulo: CLADEM.

(2016b). Balance Regional. Niñas madres. Embarazo infantil y maternidad infantil forzada en América Latina y El Caribe. Recuperado de http://clademargentina.com.ar/wp-content/ uploads/2017/03/Ni\%C3\%B1as-Madres-BalanceRegional.pdf

(2017). Tejiendo estrategias feministas para prevenir sancionar y erradicar el embarazo infantil forzado en américa latina y el caribe. Asunción: CLADEM. Recuperado de http://www. codajic.org/sites/www.codajic.org/files/Tejiendo_ Estrategias_EIF.pdf

Comisión Interamericana de Derechos Humanos (2011). Acceso a la Justicia para mujeres víctimas de violencia sexual en Mesoamérica (OEA/ Ser.L/V/II). Recuperado de https://www.cidh.oas. org/pdf\%20files/MESOAMERICA $\% 202011 \% 20$ ESP\%20FINAL.pdf

Dador, María (2011). Barreras para el acceso a los derechos reproductivos. La penalización del aborto en casos de embarazo por violación. Jurisprudencia Argentina, 9 (2011-II).

Díaz, Juan \& Ramírez, Beatriz (2013) El aborto y los derechos fundamentales. Análisis de la constitucionalidad de la prohibición penal de la interrupción del embarazo en supuestos de violación sexual y de malformaciones fetales incompatibles con la vida extrauterina. Lima: Centro de promoción y defensa de los Derechos Sexuales y Reproductivos (PROMSEX). 
Facio, Alda (2009). Metodología para el análisis de género del fenómeno legal. En: R. Santamaría (Comp.), El Género en el derecho: ensayos críticos. Quito: Serie Justicia y Derechos Humanos.

Fernández Ortega y otros vs. México (Corte Interamericana de Derechos Humanos, 30 de octubre de 2008). Recuperado de

http://www.corteidh.or.cr/CF/jurisprudencia2/ ficha_tecnica.cfm?nld_Ficha=338

Fernández Revoredo, Marisol (2013). Manual de Derecho de Familia. Lima: Fondo Editorial Pontificia Universidad Católica del Perú.

Ferrando, Delia (2006). El aborto Clandestino en el Perú: Hecho y cifras. Lima: Editorial Flora Tristán.

García Muñoz, Soledad (2013). Género y Derechos Humanos de las Mujeres: Estándares conceptuales y normativos en clave de derecho internacional. En: J. Cruz y R. Vásquez (Coord.), Derecho de las mujeres en el derecho internacional. México D.F.: Fontamara.

Gonzáles y otras ("Campo Algodonero) vs. México (Corte Interamericana de Derechos Humanos, 16 de noviembre de 2009). Recuperado de http://www.corteidh.or.cr/docs/casos/articulos/ seriec_205_esp.pdf

Guerrero Vásquez, Rossina, Ramírez Zubillaga, Sara \& Gonzáles Espinoza, Macarena (2019). Relatos de las mujeres. Experiencias de embarazos con malformaciones incompatibles con la vida. Lima: Centro de Promoción y Defensa de los Derechos Sexuales y Reproductivos (Promsex) y Centro de la Mujer Peruana Flora Tristán.

Instituto Interamericano de Derechos Humanos (2008). Feminicidio: Más allá de la vulneración del derecho a la vida. San José: IIDH. Recuperado de: https://www.iidh.ed.cr/IIDH/media/1828/femicidio_ derecho_vida-2008.pdf

Llaja Villena, Jeannette \& Silva Ticllacuri, Cynthia (2016). La justicia penal frente a los delitos sexuales. Aplicación del Nuevo Código Procesal Penal en el distrito judicial de San Martin. Lima: DEMUS- Estudio para la Defensa de los derechos de la mujer.

Mantilla Falcón, Julissa. (1996). Los derechos humanos de las mujeres: algunas reflexiones. Agenda Internacional , 3(7), pág. 83-94.
(2014) El Auto 92 de la Corte Constitucional de Colombia: algunos comentarios sobre la importancia del análisis de género. En J. Llaja (Coord.) Los derechos de las mujeres en la mira. Observatorio de sentencias judiciales. (pp. 173 -193). Lima: Demus - Estudio para la Defensa de los Derechos de la Mujer.

Mecanismo de seguimiento de la Convención de Belem Do Pará (2016). Informe hemisférico sobre violencia sexual y embarazo infantil en los Estados Parte de la Convención de Belém do Pará Washington DC: MESECVI. Recuperado de: https://www.oas.org/es/ mesecvi/docs/MESECVI-Embarazolnfantil-ES.pdf

Meléndez López, Liz (2016). Hablemos de embarazos forzados y violencia sexual. Derecho y Sociedad, 47, pp. 243-257. Disponible en: http://revistas.pucp.edu.pe/index.php/derechoysociedad/article/ view/18888

Poulsen, Karen (2018). ¡Somos ciudadanas! Ciudadanía y sufragio femenino en el Perú. Lima: Escuela de Gobierno y Políticas Públicas PUCP.

Ramírez Huaroto, Beatriz (2013). Amores rotos, impactos diferentes. Reflexiones sobre las consecuencias patrimoniales del divorcio desde la perspectiva de género. En M. Torres (edit.), El divorcio en la legislación, doctrina y jurisprudencia. Causales, proceso y garantías (pág. 265-287). Lima: Gaceta Jurídica.

(2018a). El Currículo Nacional de Educación Básica en debate: derechos de la infancia y límites de la responsabilidad parental. Derecho y Sociedad, 51, pág. 89-102.

(2018b). Las familias desde los estándares de la jurisprudencia interamericana: una mirada comparada de la legislación argentina y peruana. Revista de Derecho de Familia, 84, pág. 317-339.

Rondón, Marta (2015). El impacto del embarazo luego de una violación. Argumentos para proteger la salud mental. Lima: Centro de Promoción y Defensa de los Derechos Sexuales y Reproductivos (Promsex).

Silva Ticllacuri, Cynthia (2014).Los delitos sexuales en la política criminal peruana: análisis a partir de la legislación penal y jurisprudencia. En J. Llaja (Coord.), Los derechos de las mujeres en la mira. Observatorio de sentencias judiciales (pág. 51 - 74). Lima: Demus - Estudio para la Defensa de los Derechos de la Mujer.

OMS, OPS, UNFPA \& UNICEF (2018). Acelerar el progreso hacia la reducción del embarazo en la adolescencia en América Latina y el Caribe. Washington DC: Organización Panamericana de la Salud, Fondo de Población de las Naciones Unidas \& Fondo de las Naciones Unidas para la Infancia. Recuperado de: http://iris.paho. org/xmlui/bitstream/handle/123456789/34853/9789275319765_spa. pdf? sequence $=1 \&$ isAllowed=y\&ua $=1$ 